\title{
Conflitos macroculturais \\ e a sala de aula de língua inglesa
}

\author{
Helen Betane Ferreira \\ helen.betane@yahoo.com.br \\ Universidade Federal de Goiás
}

Dilys Karen Rees

dilys_br@yahoo.com

Universidade Federal de Goiás

\begin{abstract}
Resumo
O presente artigo visa analisar o diálogo intercultural que ocorre em uma sala de aula de língua inglesa de uma escola pública da Rede Municipal de Ensino de Goiânia, capital do Estado de Goiás. Por se tratar de um estudo de cunho etnográfico, foram utilizadas as seguintes técnicas de geração de dados: a observação-participante, anotações de campo e gravações em vídeo. A partir desses instrumentos, procuramos, por meio da análise dos domínios culturais sugerida por Spradley (1980), interpretar os sentidos e os valores que os participantes atribuem às suas ações e às ações dos outros, como questionam seus papéis sociais e interpretam valores macroculturais de acordo com a sua própria microcultura. A análise dos dados demonstrou que o diálogo intercultural entre professora e alunos ocorre via embates. Também foi possível identificar os diferentes significados culturais que a sala de aula tem para a professora e para os alunos.
\end{abstract}

Palavras-chave: interculturalidade - macro e microculturas - etnografia inglês- escola pública

\begin{abstract}
This article discusses the intercultural dialogue between an English teacher and her students from a public school in Goiânia. It is a qualitative study based on ethnography in which the following instruments of generating data were used: participant observation, field notes and video recording. All the data are discussed following the ethnographic research directions and the domain analyses theory suggested by Spradley (1980). Through the cultural domains, it was possible to identify how the participants interpret theirs and
\end{abstract}


others' actions, how they question their social roles and interpret some macrocultural values according to their own microculture. The data analyses demonstrated how the intercultural dialogue between the teacher and her students is conflicted. In addition, it was possible to identify the different cultural meanings teacher and students give to the classroom.

Keywords: intercultural dialogue - macro and microcultures - ethnography English - public school

\section{Introdução}

A sala de aula é um espaço privilegiado onde conhecimentos de toda ordem são compartilhados. Não é possível, pois, que seja um ambiente isento de conflitos, visto que o professor e os alunos vivenciaram experiências culturais distintas. Pensando em tais aspectos, decidimos estudar o diálogo intercultural em uma sala de língua inglesa de uma escola pública da Rede Municipal de Ensino de Goiânia.

\section{Focalizando micro e macroculturas}

As diferentes sociedades partilham a mesma cultura, aqui concebida como o modo de viver e de classificar o mundo, o estilo de vida comum, o ser, o fazer e o agir de determinado grupo humano, regido por leis que o próprio grupo elabora ao longo de sua história e pelas relações de poder em que se inserem (NIEDERAUER, 2010, p. 103). Por sua vez, Kramsch (1998, p. 10) considera que a cultura pode ser definida “... como se referindo aos membros de uma comunidade discursiva que compartilham um espaço social, histórico e que tem concepções imaginárias em comum" 1 .

1 "...as membership in a discourse community that shares a common social space and history, and common imaginings" 
Essa última definição nos leva a considerar o papel das macro e microculturas na formulação do diálogo intercultural. Erickson (1986), que postula a existência desses níveis culturais, explica que, ao estudarmos a sala de aula, devemos considerar o caráter local das microculturas e o caráter não local das macroculturas. Elementos da cultura local, ou microcultura, ocorrem quando um grupo humano se reúne ou se associa recorrentemente. À medida que os indivíduos desse grupo social interagem, criam-se “... tradições e compreensões locais e específicas" 2 (ERICKSON, 1986, p. 128). Uma sala de aula é um exemplo de uma microcultura, já que os participantes se reúnem regularmente e ali criam tradições locais de comportamento e de relacionamento, como também um entendimento localizado das pessoas e dos eventos.

A macrocultura é, porém, não local, visto que faz parte daquilo que é recebido do grupo humano maior em que o indivíduo está inserido. Ela é recebida de forma inconsciente e é considerada como constituinte do conhecido e do familiar. Nas palavras de Galloway (1997, p. 256), "o complexo sistema de comportamento e pensamento humano, que as pessoas criam e perpetuam, ao e para se associarem, é sutil e profundo. É forjado de forma tão natural que os seus usuários atribuem-lhe o conceito de verdade universal" 3 .

Dessa forma, na perspectiva a ser adotada neste trabalho, a sala de aula tem a sua microcultura, mas é inserida, ao mesmo tempo, em uma macrocultura institucional que rege as expectativas sobre os objetivos da ação de ensino e de aprendizagem que ocorrem no contexto escolar. Por outro lado, alunos e professores são membros de outras macroculturas que,

\footnotetext{
2 “...specific local understandings and traditions"

3 "The complex system of human thought and behavior that people create and perpetuate in and for association are subtle and profound, so elementally forged as to be endowed by their bearers with the attributes of universal truths".
} 
frequentemente, divergem quanto à forma de classificar e de compreender o mundo. Exemplificando, podemos dizer que a sala de aula é inserida na macrocultura da instituição escolar que, por sua vez, é inserida na macrocultura da Secretaria Municipal de Educação. Ao mesmo tempo, a professora e os alunos são inseridos em macroculturas de classe social e de nível educacional, entre outras. Dentro dessa linha de compreensão do mundo, a sala de aula se torna um local de encontros culturais.

Tendemos, portanto, a ver e ser no mundo com base nos próprios pertencimentos culturais. Cada cultura se constitui em uma comunidade discursiva, assim na sala de aula há encontros de discursos diferentes sobre a vida, os quais provêm de diversas macro e microculturas. Agar (1994, p. 14 apud MENDES, 2010, p. 73), pontua que "as diferenças e problemas decorrentes do encontro de culturas, que usualmente são associados ao contato com línguas estrangeiras especificamente, também acontecem dentro de uma mesma língua - ou seja, diferenças acontecem dentro das linguagens assim como através delas". Portanto,

abordar a questão do ensino/aprendizagem da cultura, ou melhor, o ensino/aprendizagem de língua como cultura, insere-se nesse contexto, o de assumirmos, como pesquisadores e professores, uma postura crítica diante da nossa prática; e também enxergarmos o indivíduo, seja ele aluno ou professor dentro do contexto no qual vive, age e interage com os outros, com seus modos particulares de interpretarem o mundo à sua volta (MENDES, 2010, p. 56).

Para aprofundarmos a discussão, trazemos o conceito de languaculture formulado por Agar (1994) e ampliado por Risager (2005). Para Risager (2005, p. 191), languaculture compreende três dimensões: o potencial semântico e pragmático; o potencial poético; o potencial identitário. A primeira dimensão abarca a uniformidade e a variabilidade semântica e pragmática 
em línguas específicas. Frequentemente os estudos na antropologia focalizam as diferenças entre línguas com base nessa dimensão e, dessa maneira, é possível contrastar conceitos como "lazer" e "trabalho" entre diferentes languacultures.

A segunda dimensão é relacionada aos tipos de significado criados ao usar as estruturas fonológicas e silábicas de uma língua para inventar novos usos da língua em rimas, poesia, trocadilhos, piadas e assim por diante. A terceira dimensão, por sua vez, debruça sobre o uso de variedades que identificam o usuário sócioculturalmente. Os participantes ao usarem certas pronúncias, gírias, estruturas sintáticas se posicionam ou são posicionados sócioculturalmente como participantes de macro ou de microculturas especificas.

Pretendemos, portanto, neste artigo analisar dois momentos que ocorreram em sala de aula usando os conceitos de macro e microculturas definidos por Erickson (1986), respaldando a nossa discussão no conceito de languaculture apresentado por Risager (2005). Os dados descritos no artigo fazem parte de um estudo maior de cunho etnográfico. Em razão disso, apresentaremos, brevemente, os conceitos básicos da Etnografia, já que esta base teórica guiou todo o processo de geração, análise e discussão dos dados.

\section{Metodologia}

Segundo Rees e Mello (2011) a Etnografia foi desenvolvida inicialmente por antropólogos para estudar o comportamento e os padrões culturais de grupos sociais do ponto de vista da interpretação cultural. De acordo com as autoras,

[...] o etnógrafo observa, de maneira sistemática, intensiva e detalhada, como as pessoas se comportam e como as interações são socialmente organizadas no contexto - quais são as normas sociais, os valores 
culturais e as expectativas interacionais dos indivíduos com os quais o pesquisador desenvolve certa relação pessoal (REES e MELLO, 2011, p. 32).

Os estudos em Educação fazem uso da linha filosófica do estudo etnográfico exatamente porque ele possibilita a compreensão do grupo social escolar, as interações que nele ocorrem, os rituais, os valores e as práticas de comportamento vivenciadas nesse ambiente tão específico.

A pesquisa de cunho etnográfica lança mão de certas técnicas visando o objetivo da compreensão das macro e microculturas ali presentes. Segundo André (2005, p. 28), um trabalho pode ser caracterizado como etnográfico quando, "[e]m primeiro lugar... ele faz uso das técnicas que tradicionalmente são associadas à etnografia, ou seja, a observação participante, a entrevista intensiva e a análise de documentos".

Watson-Gegeo (1986/2010, p. 527) também faz sugestões quanto às técnicas usadas na Etnografia:

Como método, a etnografia inclui as técnicas de observação, a observação-participante (observação $e$ interação simultânea com os participantes do estudo), as entrevistas formais e informais com os participantes do estudo em situações reais, os registros em áudio ou vídeo para análises verticalizadas das interações, coleta de documentos e materiais relevantes disponíveis no contexto de pesquisa, bem como outras técnicas necessárias para responder ás perguntas de pesquisa de um determinado estudo.

Para Spradley (1980), o etnógrafo deve não apenas observar os comportamentos e os estados emocionais do grupo social pesquisado, mas também refletir sobre o significado das ações e reações dos participantes em relação ao contexto dentro do qual estão inseridos. 
Em outras palavras, o autor [Spradley] procura mostrar que a investigação qualitativa de cunho etnográfico não se circunscreve apenas à visão ética, mas apoia-se também, na êmica. O termo êmico significa "interno" (insider) e sugere que a interpretação de um fato ou valor cultural, seja de um indivíduo ou de um grupo, (...) deve levar em conta a verdade como ela é entendida pelas pessoas que vivenciam aquela determinada cultura. Essa perspectiva se alia à perspectiva ética, "externa" (outsider) que tende a ser descritiva e que observa as estruturas comportamentais do grupo cultural em foco (REES e MELLO, 2011, p. 32).

Segundo André (2005, p. 28), “o pesquisador é o instrumento principal na coleta e análise dos dados. Os dados são mediados pelo instrumento humano, o pesquisador". Assim, ao dar voz aos participantes, e a si mesmo enquanto observador participativo, o etnógrafo estará interpretando o discurso dos participantes. Essa interpretação, por sua vez, está impregnada dos pré-conceitos e experiências de vida do responsável pelo estudo. Dessa forma, Erickson (1984, p. 8) sugere,

Então eu devo, pelo menos, fazer explícito a você o ponto de vista que eu trouxe ao local estudado e sua evolução enquanto estive lá, como também o ponto de vista com que deixei o local. O objetivo desejado não é aquele, impossível, da objetividade incorpórea (eu sou um sujeito, não um objeto), mas é ter clareza ao comunicar o ponto de vista como sujeito, tanto para mim mesmo quanto para os meus ouvintes ${ }^{4}$.

${ }^{4}$ So I should at least make explicit to you the point of view I brought to the site and its evolution while I was there, as well as the point of view with which I left. The desirable goal is not the impossible one of disembodied objectivity (I am a subject, not an object) but of clarity in communicating point of view as a subject, both to myself and to my audience. 
Mesmo integrando efetivamente o contexto da pesquisa, o etnógrafo deve procurar estranhar o familiar, ou seja, ver aquilo que lhe é tão corriqueiro com o olhar de um estranho. De acordo com Erickson (1984), a vida quotidiana é invisível, sendo que, para torná-la visível, o pesquisador deve fazer perguntas do tipo "Por que isto é do jeito que é e não diferente?". Segundo o autor, quando o etnógrafo questiona o evento, permite que o evento questione seus próprios pré-conceitos. Para Erickson (1984, p. 9), "a etnografia não é um método de objetividade, mas de subjetividade disciplinada" ${ }^{5}$. Spradley (1980) também sugere que o pesquisador deve estranhar o familiar por meio de uma série de perguntas descritivas, as quais procuram proporcionar uma melhor compreensão acerca do ambiente por ele tão conhecido, porém pouco notado. Algumas perguntas sugeridas por Spradley (1980, p. 82) são:

- Espaço físico - exemplo - De que forma o espaço físico afeta os objetos?;

- Objetos - exemplo - De que maneira os objetos evocam sentimentos?;

- Atos - exemplo - De que modo os atos variam nos diferentes períodos de tempo?;

- Atividades - exemplo - Como as atividades variam em períodos de tempo diferentes? ;

- Eventos - exemplo - Como os eventos envolvem os atores?;

- Tempo - exemplo - Como as atividades são organizadas por períodos de tempo?;

- Atores - exemplo - Quais atores são ligados a quais objetivos? ;

- Objetivos - exemplo - De que forma os objetivos afetam os sentimentos?;

\footnotetext{
${ }^{5}$ The method is not that of objectivity, but of disciplined subjectivity.
} 
- Sentimentos - exemplo - De que modo os sentimentos afetam os atos?

Guiado pelas perguntas descritivas, o etnógrafo é capaz de observar seu objeto de estudo com outro olhar, um olhar mais crítico e reflexivo, isto é, um olhar ético.

Por se tratar de um estudo de cunho etnográfico, foram utilizadas algumas dessas técnicas de geração de dados no presente trabalho: a observação-participante, anotações de campo e gravações em vídeo. Com esses instrumentos, procuramos, por meio da análise dos domínios culturais sugerida por Spradley (1980), interpretar os sentidos e os valores que os participantes atribuem às suas ações e às ações dos outros, indagando sobre os papéis sociais utilizados no momento em que as ações aconteceram.

Usamos o domínio cultural definido por Spradley (1980, p. 88) como "uma categoria de significado cultural que inclui categorias menores" 6. Assim, os domínios, como categorias culturais, são constituídos de três elementos básicos: termo geral, termos incluídos e relação semântica, ilustrado no quadro a seguir, utilizado para o levantamento de domínios culturais:

A título de exemplo, usando o Termo Geral professor e a relação semântica $X$ é uma característica de $Y$, é possível preencher o quadro 1 da seguinte forma:

Quadro 1: O professor

\begin{tabular}{|c|c|c|}
\hline Termos Incluídos & Relação Semântica & Termo Geral \\
\hline$X$ & é uma característica de & $Y$ \\
\hline $\mathrm{X}$ & é uma característica de & o professor \\
\hline $\begin{array}{ll}\text { - } & \text { Ter muitas turmas } \\
\text { - } & \text { Trabalhar muito }\end{array}$ & é uma característica do & o professor \\
\hline
\end{tabular}

Fonte: Spradley (1980).

6 "...a category of cultural meaning that includes other smaller categories". 
O domínio cultural levantado é o de professor e as categorias menores são lidas da seguinte forma: ter muitas turmas é uma característica do professor; trabalhar muito é uma característica do professor. Dessa forma, o termo geral refere-se ao domínio cultural a ser analisado, os termos incluídos são as categorias menores encontradas dentro do domínio analisado. Por fim, a relação semântica faz a ligação entre os outros dois elementos do domínio cultural. A função da relação semântica é, pois, definir os termos incluídos, inserindo-os no domínio cultural.

Desse modo, o nosso trabalho se baseou em uma compreensão de que o ser humano interpreta as suas vivências a partir dos seus pertencimentos culturais em macro e microculturas. Ao se expressar verbalmente, ele pode usufruir das três dimensões da languaculture. A professora/pesquisadora traz à sala de aula o seu pertencimento cultural, como também, cada aluno o traz. A seguir, portanto, analisaremos três momentos na sala de aula a partir dessa visão cultural do ser humano.

\section{Discussão dos dados}

O contexto escolhido para a realização do estudo foi uma turma da segunda etapa do ciclo III (antiga $7^{a}$ série) de uma escola pública do município de Goiânia. A professora pesquisadora faz parte do corpo docente dessa escola há seis anos, sendo professora da turma em questão há quase três.

A pesquisa foi realizada mediante a aprovação dos pais dos alunos, os quais assinaram um termo de consentimento após serem devidamente esclarecidos acerca do teor do estudo. Essa medida foi necessária porque a turma focalizada é composta de trinta alunos com idades entre 12 e 15 anos.

Seis aulas sequenciais foram gravadas em vídeo, cada uma com duração de uma hora. Entretanto, por questões de 
espaço, restringiremos à análise de dois momentos específicos de uma aula apenas. Para que o leitor entre em contato com a microcultura dessa sala de aula, utilizaremos a "vinheta", definida por Erickson (1986, p. 149) como “... um retrato vívido da condução dos eventos cotidianos, no qual os feitos são descritos na sequência natural das suas ocorrências no tempo real" ${ }^{7}$. Vale salientar que as informações utilizadas para compor as vinhetas foram retiradas das anotações de campo, feitas pela docente ao final de cada aula, e das gravações em vídeo. Por meio dos recortes, analisaremos a influência da macrocultura na microcultura da sala de aula, observando como a cultura dos alunos e da professora pode interferir no processo de ensino e aprendizagem da língua inglesa nesse contexto. Atentaremos também para as dimensões das languacultures presentes na sala de aula.

\section{Primeiro Momento: notas de campo (03/04/2007) Vinheta 1}

O tema da aula é rotina. Utilizei esse tema para apresentar o Presente Simples. Depois do tradicional cumprimento de todas as aulas, de pedir para os alunos abrirem seus cadernos e perguntar a data do dia, escrevo um texto sobre a minha rotina no quadro e peço aos alunos que copiem. Espero alguns minutos para que a maioria termine de copiar. Então começo a fazer perguntas aos alunos individualmente sobre cada frase do texto. Depois da atividade sobre a rotina da professora, passamos para uma atividade de audição. $\mathrm{Na}$ atividade em questão, os alunos deveriam ouvir um rapaz falando da própria rotina e completar as frases com os verbos que estavam faltando.

\footnotetext{
7 “.... vavid portrayal of the conduct of an event of everyday life, in which the sights and sounds of what was being said and done are described in the natural sequence of their occurrence in real time".
} 


\section{Recorte 1: aula (03/04/2007)}

Ariel $^{8}$ : Teacher, olha a minha letra!

T: Amém! Até que enfim a coisa está saindo bem feita!

Ariel: Olha o cara fumando um baseado (mostrando o desenho que ele fez)!

T: Mas precisava? Você vai ver que não vai dar certo! Ele não fuma!

Ariel: Fuma sim, professora! Ele fuma escondido.

T: Fuma nada!

Ariel: Ele fala que não fuma, mas ele fuma um baseado. Cê quer um pirulito, professora? (rindo)

Ângelo: Teacher, como é que fala doizinho em inglês?

T: Doizinho?

Fabiano: Dois no diminutivo.

Ariel: Doizinho em inglês! (rindo)

T: Little two?

Ariel: Eh, João, tá fumando um little two, né?

T: Finished?

Ariel, no recorte, traz à tona um aspecto aparentemente comum à microcultura dele próprio e dos demais alunos: o mundo das drogas. A inserção deste assunto foi inesperada, já que nem o texto, nem a atividade proposta se referiam a qualquer atividade que não fosse lícita. Considerando o material didático, Gray (2002, p. 157), na sua discussão de livro didático globalizado, aponta o fato que esses livros são "sutilmente desterritorializados" e que os autores seguem diretrizes que abrangem duas áreas: a inclusividade e as inadequações. Os livros, consequentemente, não devem usar uma linguagem sexista para se referir às mulheres e devem evitar tópicos que possam ser ofensivos ou inadequados aos possíveis compradores espalhados pelo mundo. Assim, os assuntos abordados são os mais inofensivos possíveis. Magno e Silva (2009, p. 62), por sua vez, apontam que os textos em livros didáticos "revelam-se pesadamente artificiais" e os diálogos tendem a enfocar o vocabulário e as estruturas gramaticais e não a vivência real do

\footnotetext{
${ }^{8}$ Todos os nomes aqui utilizados são fictícios.
} 
aluno. É possível, portanto, postular uma macrocultura em que os livros didáticos e paradidáticos se inserem. Nessa cultura não há menção às drogas, ao uso exagerado da bebida alcoólica, à violência ou a quaisquer atividades e situações que não façam parte de um comportamento social dentro dos preceitos legais. Logo, o material didático usado pela professora reflete uma macrocultura que não reconhece qualquer comportamento ilícito.

Além disso, podemos afirmar que a microcultura da professora difere em vários aspectos daquela dos alunos. Primeiro, a professora se insere dentro de uma cultura pedagógica que compreende a sala de aula como local de ensino que, por sua vez, se insere dentro de uma macrocultura da didática de ensino de língua estrangeira. Essa didática inclui estratégias e técnicas com o intuito de apresentar e depois praticar pontos específicos do conteúdo programático, visando o domínio gradual da língua inglesa por parte dos alunos. A inserção nessa macrocultura se inicia na universidade ao fazer o curso de licenciatura e ao se tornar uma profissional de ensino (cf. CELANI, 2006). Há, portanto, certas expectativas e posicionamentos em relação ao que deve ocorrer em sala de aula provenientes dessa macrocultura.

Ao mesmo tempo, a macrocultura da didática da professora não existe somente dentro de um conceito geral e idealizado da sala de aula, mas foi localizada pelas suas ações numa escola pública municipal. Isto é, as expectativas e as práticas foram adaptadas a essa realidade. Exemplificando, ao pedir que os alunos copiassem o texto do quadro, a professora se adaptou a uma realidade sem livro didático, em que o material é fotocopiado ou copiado do quadro. No momento da aula, o ponto funcional sendo considerado é a rotina com o uso do Presente Simples. A rotina, geralmente, inclui o ensino de vocabulário para descrever atividades como acordar, levantar da cama, escovar os dentes, tomar café, ir para a escola, jogar futebol, empinar pipa e assim por diante. Dentro das rotinas trabalhadas 
em sala de aula, há certos tópicos que podem ser considerados tabus como o uso do banheiro, as práticas sexuais e a familiarização de mundos ilícitos. Lembramos que a turma observada era de crianças menores de idade.

Ao mesmo tempo em que a professora, como profissional do ensino, se insere em uma macrocultura de didática, ela se insere também em uma microcultura que não conhece o mundo das drogas. Esse mundo não faz parte da sua rotina e, no momento da aula, nunca lhe ocorreu que poderia aparecer tal assunto. Ariel e Ângelo, entretanto, demonstram que o mundo das drogas não lhes é estranho. $\mathrm{O}$ vocabulário para denominar a droga parece ser bastante familiar não somente para eles, mas para toda a turma. A partir das suas falas, geramos o seguinte domínio cultural (quadro 2):

Quadro 2: Droga

\begin{tabular}{|l|c|c|}
\hline \multicolumn{1}{|c|}{$\begin{array}{c}\text { Included Terms } \\
\text { (termos incluídos) }\end{array}$} & $\begin{array}{c}\text { Semantic Relationship } \\
\text { (relação semântica) }\end{array}$ & $\begin{array}{c}\text { Cover Terms } \\
\text { (termo geral) }\end{array}$ \\
\hline$X$ & é um meio de denominar & $Y$ \\
\hline $\begin{array}{l}\text { baseado; } \\
\text { doizinho; } \\
\text { pirulito }\end{array}$ & são meios de denominar & Droga \\
\hline
\end{tabular}

Fonte: Spradley (1980).

A professora entendeu o uso da palavra baseado, mas não a palavra doizinho. Notamos que ela tenta se portar naturalmente diante do tema quando traduz literalmente a palavra doizinho para o inglês como little two em tom de interrogação. O momento marca o encontro conflituoso de microculturas diferentes: uma em que o uso ilegal das drogas causa estranhamento e outra em que esse uso ilícito é familiar. De fato, vivemos na polaridade entre o familiar e o estranho. Para esclarecer essa vivência, recorreremos à filosofia hermenêutica de Gadamer (1999) em que as palavras familiar e estranho não 
são formas de avaliar aquilo que nos cerca. Ao contrário, descrevem a maneira como nos situamos em relação aos eventos que ocorrem. Em outras palavras, são modos de existência dentro de situações interpretativas que vivemos. O familiar, nessa acepção, não significa um objeto próximo e conhecido, mas é definido existencialmente como uma experiência que nos conforta e nos afirma positivamente. Por outro lado, o estranho é uma situação que nos traz sentimentos de desorientação e perda (cf. KERDEMAN, 1998). O constrangimento e a desorientação da professora com a situação é aparente, demonstrando o seu estranhamento com o assunto proveniente de outra microcultura. Ela não leva adiante a discussão e marca o término do tópico dizendo: Finished?.

Considerando o aluno Ariel, constatamos que, ao desenhar um rapaz fumando um baseado, ele rompe com a macrocultura da estrutura de uma aula de língua estrangeira. Ao dizer Olha o cara fumando um baseado, Ariel usa a língua para se identificar socioculturalmente, isto é, ele se identifica como alguém que conhece o mundo das drogas. Retomando Risager (2005), Ariel usa a língua no seu potencial identitário. Em seguida, ao oferecer um pirulito à professora, ele ressalta ainda mais este pertencimento e o fato de que ela não faz parte dessa microcultura. Esse não pertencimento pode ser relacionado à posição de autoridade da professora como representante da instituição escolar, já que a escola não aceita ou reconhece como válido o mundo das drogas. O aluno Ângelo, ao pedir a tradução da palavra doizinho, posiciona-se como alguém que se identifica com a microcultura do mundo das drogas e, portanto, fora da microcultura da professora. Por outro lado, ao pedir a tradução, ele se coloca como aluno interessado, mas em ruptura, visto que deseja a tradução de uma palavra que se refere a um mundo ilícito e não legitimado pela macrocultura da didática de ensino de línguas estrangeiras ou pela macrocultura institucional. Nesse momento, os alunos demonstram ter mais conhecimento e 
familiaridade com o assunto do que a professora. Os papéis são invertidos, visto que são os alunos que ensinam à professora o vocabulário para se referir às drogas.

Assim a professora precisa lidar com as rupturas em suas expectativas do que seja o conteúdo apropriado para uma sala de aula de L2. Ao passar pela vivência dessa desorientação e perda, ela, em seguida, poderá decidir como proceder em sala de aula quando o assunto de drogas vir à tona. As possibilidades são várias: ela poderá discutir os malefícios do uso das drogas; discutir as razões que levam ao uso delas; ou trabalhar em conjunto sobre esse tópico com professores de outras disciplinas, e assim por diante.

\section{Segundo Momento: notas de campo (03/04/2007) Vinheta 2}

Ignorando demais comentários sobre quem fuma o quê, tentei dar continuidade à atividade de audição. Primeiro pedi aos alunos que lessem as frases e fizessem perguntas sobre as palavras desconhecidas antes de ouvirem a fita e completarem as frases com os verbos que faltavam.

\section{Recorte 2a: aula $(03 / 04 / 2007)$}

T: Ó como é que escreve "football". Teve gente que não tava dando conta de escrever "football" na aula passada. In English é assim (mostrando a palavra escrita no quadro).

Ângelo: Ou senão "soccer".

T: Soccer is American (for futebol). Dias da semana a gente sempre escreve com letra maiúscula. Não me põe dia da semana com letra minúscula!

(Fabiano e David comentam sobre a violência do futebol americano. Alex e Iasmim estão trocando socos).

T: Quietos vocês dois! Vou ter que mudar vocês dois de lugar? Que coisa!

1S: Professora, ele fica puxando o cabelo da Iasmim.

T: Ah, desconfia Alex!

Alex: Ah! Ela fica olhando para trás (rindo)!

Vagner: Teacher, às vezes a gente brinca de futebol americano.

Ariel: Só que a Joelma (Coordenadora de turno) pegou nós! 
T: Para jogar futebol americano é preciso conhecer as regras. Todo jogo tem regras!

Ariel: Não professora! A gente sai arrebentando todo mundo, professora! É facinho jogar!

T: O que a Joelma falou?

Ariel: Falou que era muito perigoso (rindo)!

Recorte 2b: aula (03/04/2007)

$\mathrm{T}$ : Number nine.

Breno: He... noon to...

(Neste momento, o aluno Alex mexe com o João. Ao assistir à gravação, não dá para ver exatamente o que acontece. João vira para trás e diz: "Vou meter bala na sua cara!". Alex ri. Fabiano também acha graça. No momento da aula, não visualizo o acontecimento).

A partir desta vinheta podemos averiguar a quantidade de ações que ocorrem ao mesmo tempo na sala de aula e que requerem a atenção da professora. No Recorte $2 \mathrm{a}$, há um incidente que a professora não conseguiu captar enquanto ocorria. Referindo-nos à macrocultura da didática de ensino de línguas estrangeiras, com a qual a professora entrou em contato inicialmente na universidade, podemos afirmar que este arcabouço de informação sobre estratégias e técnicas de ensino não forneceu subsídio para lidar com a situação real da sala de aula de uma escola pública. A sala de aula com tantos alunos e com tantas necessidades diversas necessita de um saber construído na prática do dia a dia, isto é, a práxis de ensino. Apontamos que o estudo maior do qual este artigo faz parte buscou ampliar o saber da professora sobre a própria prática. Em decorrência do tipo de sala de aula, cheio de ações diversas, a professora tenta manter-se focada na lição agindo dentro da macrocultura da didática e prática aprendida em que se deve seguir o plano de aula e apresentar e exercitar o conteúdo programático daquele dia letivo. Dessa maneira, a professora continua a insistir sobre o diálogo apresentado e tenta ajudar os 
alunos a aprender o vocabulário que faz parte do tópico do dia: rotina.

É interessante observar mais uma vez a influência da microcultura dos alunos na aula. Alguns sabem da existência de um esporte pouco conhecido e praticado no Brasil, provavelmente através de filmes veiculados na televisão. Outros confundem soccer (futebol) com futebol americano. O aluno que mais fala sobre futebol americano é Ariel e, através das falas dele, podemos formular o domínio cultural futebol americano (quadro 3).

Quadro 3: Futebol americano

\begin{tabular}{|l|c|c|}
\hline \multicolumn{1}{|c|}{$\begin{array}{c}\text { Included Terms } \\
\text { (termos incluídos) }\end{array}$} & $\begin{array}{c}\text { Semantic Relationship } \\
\text { (relação semântica) }\end{array}$ & $\begin{array}{c}\text { Cover Terms } \\
\text { (termo geral) }\end{array}$ \\
\hline Arrebentar todo mundo & é uma atribuiçãode & $Y$ \\
Fácil de jogar & é uma atribuição & do futebol americano \\
$\begin{array}{l}\text { Desnecessário saber as } \\
\text { regras }\end{array}$ & & \\
\hline
\end{tabular}

Fonte: Spradley (1980).

Analisando as suas falas, percebemos que o tema futebol americano é equacionado à violência. Sabemos que para aqueles que não conhecem as regras do jogo, o fato de os jogadores se amontoarem uns em cima dos outros pode ser interpretado como um ato aleatório de violência. Contudo, há regras explícitas sobre quando e como contato físico entre os jogadores é permitido. Para o aluno Ariel, no entanto, a característica principal desse esporte é a possibilidade de arrebentar todo mundo, isto é, o jogo é uma oportunidade de dar vazão à violência. Segundo o aluno é facinho jogar e não é preciso saber as regras, já que o objetivo do jogo é poder arrebentar os outros. Logo, o futebol americano, na visão de Ariel, não é um jogo praticado em outro país, mas é um nome dado às brincadeiras violentas praticadas 
durante o recreio. O domínio cultural futebol americano tem significados culturais específicos na acepção desse aluno. Dessa forma, é possível afirmar que na primeira dimensão da languaculture, o termo futebol americano no potencial semântico se difere do significado em outras microculturas, tornando-se, no potencial identitário, um termo que ajuda a definir Ariel socioculturalmente.

Concomitantemente à discussão sobre futebol americano, outras ações, imperceptíveis aos olhos da professora, ocorrem dentro do ambiente de sala de aula. Em uma delas Alex e Iasmim trocam socos. Alguns instantes depois, no segundo recorte, Alex se envolve em um desentendimento com João. João ameaça: "Vou meter bala na sua cara". A agressividade expressa na ação e nas palavras dos alunos, aparentemente, faz parte da microcultura deles. Essa violência se manifesta no desejo de poder "arrebentar os outros", na provocação de um aluno contra o outro (Alex - Iasmim, Alex - João) e na reação à provocação (João - Alex). A sala de aula, por conseguinte, é um lugar de conflito entre os alunos.

Mais uma vez, houve uma ruptura nas expectativas da professora sobre o que transcorreria na sala de aula, visto que ela foi surpreendida pela interpretação do aluno Ariel sobre o tema futebol americano. Novamente, há estranheza sobre o que ocorre em sala de aula. Assim, a professora, para continuar a atuar neste tipo de sala de aula, precisa aprender a conviver com a violência que aparece tanto na fala quanto nas ações dos alunos. Essa convivência, a nosso ver, não deve ser passiva, mas ser uma luta constante para mostrar que há outras maneiras de lidar com o ímpeto da violência que existe dentro de cada ser humano e que está banalizado na sociedade contemporânea. No caso da discussão sobre o jogo de futebol americano, a professora tenta frear a violência ao dizer, "Todo jogo tem regras", mostrando que o futebol americano não é uma desculpa para violência desenfreada. Em relação a Alex e Iasmim, ela 
chama atenção dos dois para que parem de se agredir. Quanto ao João, o que ele fala não é ouvido pela professora durante a aula. A fala de João só é percebida quando a professora assistiu à gravação em vídeo.

Os dados apresentados ratificam o fato de que a sala de aula de língua inglesa da Rede Municipal de Ensino de Goiânia, foco dessa análise, é um espaço rico de saberes. O fato de os participantes deste ambiente, alunos e professora, pertencerem a diferentes macro e microculturas faz com que diálogo intercultural ocorra via conflitos, cujos enfrentamentos exigem uma maior e melhor preparação por parte da docente participante deste estudo.

Em relação ao significado cultural da sala de aula é possível formular duas tabelas:

Tabela 1 - Significado cultural da sala de aula para a professora

\begin{tabular}{|l|c|c|}
\hline \multicolumn{1}{|c|}{$\begin{array}{c}\text { Included Terms } \\
\text { (termos incluídos) }\end{array}$} & $\begin{array}{c}\text { Semantic } \\
\text { Relationship } \\
\text { (relação semântica) }\end{array}$ & $\begin{array}{c}\text { Cover Terms } \\
\text { (termo geral) }\end{array}$ \\
\hline \multicolumn{1}{|c|}{ X } & é uma atribuição de & Y \\
\hline $\begin{array}{l}\text { Ensinar o plano de aula sobre o } \\
\text { Presente Simples usado em rotinas; } \\
\text { (“Dias da semana a gente sempre } \\
\text { escreve com letra maiúscula") - } \\
\text { Recorte 2a; }\end{array}$ & é uma atribuição de & Sala de aula \\
\hline $\begin{array}{l}\text { Ordem ("Vou ter que mudar vocês } \\
\text { dois de lugar") - Recorte 2a; }\end{array}$ & & \\
\hline $\begin{array}{l}\text { Interação ("O que Joelma } \\
\text { falou?") - Recorte 1. }\end{array}$ & & \\
\hline
\end{tabular}


Tabela 2 - O significado cultural da sala de aula para os alunos:

\begin{tabular}{|l|c|c|}
\hline \multicolumn{1}{|c|}{$\begin{array}{c}\text { Included Terms } \\
\text { (termos incluídos) }\end{array}$} & $\begin{array}{c}\text { Semantic } \\
\text { Relationship } \\
\text { (relação semântica) }\end{array}$ & $\begin{array}{c}\text { Cover Terms } \\
\text { (termo geral) }\end{array}$ \\
\hline \multicolumn{1}{|c|}{$X$} & é uma atribuição de & $Y$ \\
\hline $\begin{array}{l}\text { Participar no tópico da aula } \\
\text { (Ângelo: "Ou senão soccer") }- \\
\text { Recorte 2a; }\end{array}$ & & \\
\hline $\begin{array}{l}\text { Participar desviando o tópico } \\
\text { (Ariel: Olha o cara fumando um } \\
\text { baseado (mostrando o desenho que } \\
\text { ele fez!) - Recorte 1; }\end{array}$ & \\
\hline $\begin{array}{l}\text { Interagir com os colegas de forma } \\
\text { violenta (Alex e Iasmim estão } \\
\text { trocando socos) - Recorte 2a; } \\
\text { João vira para trás e diz: "Vou } \\
\text { meter bala na sua cara!”) - Recorte } \\
\text { 2b. }\end{array}$ & \\
\hline
\end{tabular}

Ao examinar as tabelas, constatamos que a sala de aula tem atribuições diferentes para a professora e para os alunos. $\mathrm{O}$ termo sala de aula, na verdade, tem valores semânticos diferentes e consequentemente se constitui em pelo menos dois domínios culturais dependendo de quem o define. A professora, então, ao lidar com a sala de aula, precisa compreender como este espaço tem significações culturais diversas. Nessa visão, o comportamento dos alunos não pode ser classificado de forma simples, como errado ou inadequado, mas deve ser visto como inserido em uma construção microcultural em que a sala de aula se torna o palco da vivência diária com as drogas, com os conflitos com a autoridade, com o uso da agressividade, mas ao mesmo tempo com o interesse em participar da aula de alguma forma e compartilhar experiências. Ao postular uma interpretação cultural, é possível fugir de uma visão binária de 
certo e errado em relação ao comportamento do aluno como também fugir de uma visão rígida sobre o tipo de planejamento necessário para a aula de língua estrangeira - inglês. A aula, na visão cultural, pode se tornar uma ponte intercultural entre o que a professora sabe sobre a língua estrangeira e sobre o ensino dessa língua e o que o aluno vivencia, com o objetivo de ajudá-lo a vislumbrar novos horizontes culturais.

\section{Considerações finais}

Nesse artigo, portanto, examinamos os eventos da sala de aula do ponto de vista das macro e microculturas e as relações de pertencimento a essas culturas. Ficou demonstrado que a sala de aula é um local de conflitos e embates culturais e que a professora se viu tendo que lidar de forma imediata com as rupturas que ocorreram no decorrer da aula.

\section{Referências}

AGAR, Michael. Language shock: understanding the culture of conversation. New York: William Morrow, 1994.

ANDRÉ, Marli El. D. A. Etnografia da prática escolar. Campinas, SP: Papirus, 12 ed., 2005.

CELANI, Maria Antonieta A. Ensino de línguas estrangeiras: ocupação ou profissão? In: LEFFA, Vilson. O professor de línguas estrangeiras: construindo a profissão. Pelotas: EDUCAT, 2006. p. 2343.

ERICKSON, Frederick. What makes school ethnography 'ethnographic'? In: Anthropology and Education Quarterly, v. 15, p. 51-66, 1984. 
ERICKSON, Frederick. Qualitative methods in research on teaching. In: WITTROCK, Merlin C. (Ed.) Handbook of research on teaching. 3 ed. New York: Macmillan, 1986. p. 119-161.

GADAMER, Hans-Georg. Verdade e método. 3 ed. Tradução de F.P. Meurer. Petrópolis: Vozes, 1999.

GALLOWAY, Vicki. Toward a cultural reading of authentic texts. In: HEUSINKVELD, Paula R. (Ed.). Pathways to culture. Yarmouth: Intercultural Press, 1997. p. 255-302.

GRAY, John. The global coursebook in English language teaching. In: BLOCK, David.; CAMERON, Deborah (Eds). Globalization and language teaching. New York: Routledge, 2002. p. 151-167.

JIN, Lixian; CORTAZZI, Martin. The culture the learner brings: a bridge or a barrier? In: BYRAM, Michael; FLEMING, Michael (Ed.). Language learning in intercultural perspective. Cambridge: Cambridge University Press, 1998. p. 98-118.

KERDEMAN, Deborah. Between Interlochen and Idaho: hermeneutics and education for understanding. Philosophy of Education, 1998.

MAGNO E SILVA, Walkyria. Livros didáticos: fomentadores ou inibidores da autonomização? In: DIAS, Reinildes; CRISTOVÃO, Vera Lúcia L. (Orgs). O livro didático de língua estrangeira; múltiplas perspectivas. Campinas: Mercado de Letras, 2009. p. 57-88.

MENDES, Edleise. Por que ensinar língua como cultura? In: SANTOS, Percilia; ORTIZ ALVAREZ, Maria Luisa (Orgs.). Língua e cultura no contexto de português língua estrangeira. Campinas, SP: Pontes Editores, 2010. p. 53-77.

NIEDERAUER, Marcia Elenita F. Estranhamentos culturais em sala de aula de português para estrangeiros. In: SANTOS, Percilia; ORTIZ ALVAREZ, Maria Luisa (Orgs.). Língua e cultura no contexto de português língua estrangeira. Campinas, SP: Pontes Editores, 2010. p. 101-121. 
REES, Dilys Karen; MELLO, Heloísa A. B. A investigação etnográfica na sala de aula de segunda língua/ língua estrangeira. Cadernos do IL, n. 42, p. 30-50, junho de 2011. Disponível em: http://www.seer.ufrgs.br/cadernosdoil/. Acesso em 15 mar. 2014.

RISAGER, Karen. Languaculture as a key concept in language and culture teaching. In: PREISLER, Bent; FABRICIUS, Anne; HABERLAND, Hartmut; KJAERBECK, Susanne; RISAGER, Karen (Eds). The consequence of mobility. Roskilde: Roskilde University, 2005. p. 185-196.

SPRADLEY, James. Participant observation. Fort Worth: Harcourt Brace College Publishers, 1980.

WATSON-GEGEO, Karen Ann. A etnografia na sala de aula de segunda língua: definindo o que é essencial. Trad. Heloísa Augusta Brito de Mello e Dilys Karen Rees. Signótica, v. 22, n. 2, p. 515-539, 2010 .

Recebido em: 11/10/2014 Aceito em: 17/09/2015

Title: Macroculture conflicts and the English language classroom 